\title{
EOPs: Suplementación de vitamina B12 en pacientes con déficit crónico
}

Vitamin B12 supplementation in patients with chronic deficiency

María de las Nieves Ganiele ${ }^{\dagger}$

\begin{abstract}
Resumen
El déficit de vitamina B12 suele aumentar con la edad y debe ser sospechado en casos de macrocitosis, pancitopenia de origen incierto o síntomas neurológicos que sugieran neuropatía periférica, demencia, etc. Su diagnóstico inicial se explora mediante la determinación sérica de vitamina B12 y ácido fólico. Tradicionalmente el tratamiento de esta entidad consistió en su suplementación por vía parenteral.

A partir de una viñeta clínica de una paciente con deficiencia de vitamina B12 se planteó el interrogante de la pertinencia del tratamiento suplementario con vitamina B12 por vía oral. Se formuló una pregunta clínica con "formato PICO*", se realizó una búsqueda bibliográfica y se identificaron dos artículos cuyas conclusiones ayudaron a responder que la suplementación con vitamina B12 por vía oral es a su vez eficaz y aceptada por los pacientes con deficiencia de vitamina B12 de cualquier etiología.

\section{Abstract}

Vitamin B12 deficiency tends to increase with age and should be suspected in cases of macrocytosis, pancytopenia of uncertain origin or neurological symptoms suggestive of peripheral neuropathy, dementia, etc. Diagnosis is initially conducted by determining serum vitamin B12 and folic acid concentrations. Traditionally, treatment consisted in its supplementation via intramuscular injections.

From a clinical vignette of a patient with vitamin B12 deficiency, a question was raised about the relevance of supplementary treatment with oral vitamin B12 formulations. Using a "PICO format" question, the author conducted a literature search and identified two articles whose findings helped to answer that vitamin B12 oral supplementation is both effective and accepted by patients.
\end{abstract}

Palabras clave: Déficit de vitamina B12, cianocobalamina, tratamiento. Key words: Vitamin B12 deficiency, cyanocobalamin, treatment.

Ganiele M. Suplementación de vitamina b12 en pacientes con déficit crónico. Evid Act Pract Ambul. Oct-Dic 2011;14(4):158-159

\section{Escenario Clínico}

Un médico de familia atiende a un paciente varón de 60 años tabaquista e hipertenso, medicado con nebivolol y rosuvastatina, que consultó por parestesias en ambos pies, de varios meses de evolución. Estudios solicitados por este motivo revelaron (solo datos positivos): un hemograma con macrocitosis [hematocrito 44,2\%; hemoglobina 15g/dl; VCM 107,3fl (VN 81 a $97 \mathrm{fl}$ ), leucocitos $8.400 / \mathrm{mm} 3]$, alteraciones en los niveles de vitamina B12 [121pg/ml (VN: >239]; y un electromiograma que mostró neuropatía distal de grado leve.

Frente a estos resultados el médico establece un diagnóstico provisional de neuropatía periférica por déficit de vitamina B12, y mientras decide seguir investigando su causa, y surge la duda acerca de cuál sería la dosis adecuada y mejor forma de administración de vitamina B12 suplementaria.

\section{Pregunta que generó el caso}

En pacientes adultos con déficit moderado de vitamina B12 (población), ¿cuál es la dosis adecuada y mejor vía de administración de vitamina B12 (intervención), útil para normalizar sus niveles y los de ácido metilmalónico (resultado)?

\section{Estrategia de búsqueda}

Se realizó la búsqueda en PubMed utilizando como palabras clave "vitamin B12 deficiency" y "drug therapy" poniendo como límites: humans, all adults, english, last 10 years.

La búsqueda arrojó varios trabajos entre los cuales se eligieron los más relacionados a la pregunta formulada.

\section{Algunas consideraciones acerca del déficit de vitamina B12}

La incidencia del déficit de vitamina B12 (cobalamina) aumenta con la edad. Existe un amplio espectro de síntomas que puede presentar un paciente con este déficit y su diagnóstico temprano y tratamiento adecuado pueden revertirlos 1 . de las manifestaciones clínicas encontramos guientes: a) hematológicas (anemia megaloblástica, pancitope- nia), neurológicas (parestesias, neuropatía periférica), desordenes neuropsiquiátricos (irritabilidad, demencia, alteración de la memoria, depresión, psicosis), cardiovasculares (posible aumento del riesgo de infarto agudo de miocardio)'.

El déficit de vitamina B12 produce aumento de los niveles séricos de homocisteína y de acido metilmalónico, su medición es mucho más sensible para diagnosticarlo que el nivel sérico de vitamina $\mathrm{B} 12^{2}$.

Una vez que se confirma el diagnóstico de déficit de vitamina B12 se debe investigar la etiología. Las causas se pueden dividir en tres: deficiencias nutricionales (pacientes alcohólicos, añosos o vegetarianos), síndromes de malabsorción (uso prolongado de bloqueantes $\mathrm{H} 2$ e inhibidores de la bomba de protones, anemia perniciosa, gastritis atrófica) y otras causas gastrointestinales (resección ileal, enfermedad de Crohn, sobrecrecimiento bacteriano $)^{3}$.

El tratamiento tradicional suele ser por vía parenteral (intramuscular) con dosis diarias de $1000 \mu \mathrm{g}$ por una semana, seguido de $1000 \mu \mathrm{g}$ semanales por un mes y luego $1000 \mu \mathrm{g}$ mensual si persiste el déficit. Por vía oral la dosis recomendada es 1.000 a $2.000 \mu \mathrm{g} /$ día. Este régimen ha demostrado ser seguro, rentable y bien tolerado por los pacientes ${ }^{3,4}$.

\section{Resumen de la evidencia}

Eussen SJ, de Groot LC, Clarke R, et al. Oral cyanocobalamin supplementation in older people with vitamin B12 deficiency: a dose-finding trial. Arch Intern Med. 2005;165:1167-72.

Se trata de un estudio aleatorizado, de grupos paralelos ${ }^{*}$, doble ciego que buscó determinar la menor dosis efectiva de cianocobalamina necesaria para normalizar los marcadores bioquímicos en adultos con déficit leve de vitamina B12, definido como una concentración sérica de vitamina B12 de 135 a $406 \mathrm{pg} / \mathrm{ml}$ y un nivel de ácido metilmalónico mayor o igual a $0,26 \mu \mathrm{mol} / \mathrm{ml}$. Las dosis evaluadas fueron $2,5,100,250,500$, y $1000 \mu \mathrm{g}$, administrada durante 16 semanas por vía oral. La muestra incluyó a 120 personas sanas mayores de 70 años. La

+ Servicio de Medicina Familiar y Comunitaria del Hospital Italiano de Buenos Aires maria.ganiele@ hospitalitaliano.org.ar * Ver glosario 
medida de resultado principal fue la dosis de cianocobalamina oral que produzca un reducción máxima estimada en la concentración plasmática de ácido metilmalónico del $80 \%$ al $90 \%$. La suplementación con cianocobalamina en dosis orales diarias de 2,5, 100, 250, 500 y $1000 \mu \mathrm{g}$ se asoció con reducciones medias en las concentraciones plasmáticas de ácido metilmalónico de $16 \%, 16 \%, 23 \%, 33 \%$ y $33 \%$, respectivamente. Los resultados mostraron que la dosis diaria necesaria para alcanzar el resultado principal varía de 647 a $1.032 \mu \mathrm{g}$. Los autores concluyeron que la dosis más baja de cianocobalamina por vía oral para normalizar la deficiencia es 200 veces mayor que el consumo dietético recomendado ( $3 \mu \mathrm{g}$ diarios).

Kwong JC, Carr D, Dhalla IA, et al. Oral vitamin B12 therapy in the primary care setting: a qualitative and quantitative study of patient perspectives. BMC Fam Pract. 2005;6(1):8.

En este estudio se investigaron las perspectivas de los pacientes sobre el cambio de la terapia con vitamina B12 de la vía intramuscular a la vía oral. Presento dos ramas: una cuantitativa, en donde se utilizaron cuestionarios, y otra cualitativa, que se basó en entrevistas semi-estructuradas. Se incluyeron 133 pacientes que recibían inyecciones regulares de vitamina B12 de los cuales 86 respondieron los cuestionarios. El 73\% (63/86) de los encuestados estaban dispuestos a cambiar a vitamina B12 oral. En un análisis multivariado*, dentro de los fac- tores asociados con "la voluntad de cambiar" se incluían: ser capaz de llegar a la clínica en menos de 30 minutos $\left(\mathrm{OR}^{*} 9,3\right.$; IC 95\%: 2,2 a 40,0), que encontraban como desventajas de la terapia intramuscular las visitas frecuentes al hospital (OR 5,4; IC 95\%: 1,1 a 26,6 ) y el aumento que esta genera en los costos al sistema de salud (OR 16,7 IC 95\%: 1,5 a 184,2). De los 55 pacientes que finalmente intentaron el cambio a la vía oral, el $76 \%(39 / 51)$ estaba satisfecho y el $71 \%$ (39/55) deseaba cambiar de forma permanente.

Los autores concluyeron que el cambio a la terapia oral es factible, que los suplementos orales de B12 son aceptados principalmente por una mayor comodidad y que los médicos deberían ofrecerla a todos sus pacientes.

\section{Conclusiones y comentarios}

A partir de la búsqueda realizada se puede afirmar que el tratamiento de reemplazo por vía oral es eficaz sin importar la causa de la deficiencia, ya que la vitamina B12 tiene un segundo mecanismo de absorción independiente del factor intrínseco (aproximadamente el 1\% de la dosis oral), pero se deben utilizar altas dosis por su absorción variable. Esta vía de administración es aceptada por los pacientes y puede resultar mucho más cómoda para ellos. Al indicar este tratamiento hay que evaluar cuál es la vía más adecuada para cada paciente y ofrecerle ambas opciones.

\section{Referencias}

1. Oh L, Brown DL. Vitamin B12 deficiency. Am Fam Physician. 2003;67(5):979-86.

2. Schrier SL. Diagnosis and treatment of vitamin B12 and folic acid deficiency. In: UpToDate, Basow, DS (Ed), UpToDate, Waltham, MA, 2011.

3. Schrier SL. Etiology and clinical manifestations of vitamin B12 and folic acid deficiency. In: UpToDate, Basow, DS (Ed), UpToDate, Waltham, MA, 2011.

4. Andrès E, Dali-Youcef N, Vogel T, Serraj K, Zimmer L. Oral cobalamin treatment. An update. Int Jnl Lab Hem. 2009;31:1-8. 